\title{
Fronteras Brasil y Perú, espacio de integración y cooperación
}

\author{
Itala Laurente* \\ Eduardo Ernesto Filippi*
}

\section{Resumen}

Las fronteras son espacios donde se condensan las relaciones entre la población local y los diferentes niveles de gobierno, sea nacional o subnacional. Por eso, es relevante la creación de áreas fronterizas de paz y desarrollo sustentable, con base en la cohesión regional, integración social y territorialidad, lo que contribuye a la disminución de las tensiones entre los países y consolida los procesos de integración y cooperación continua. Particularmente, las fronteras de Brasil y Perú tienen una relevancia estratégica a razón de la biodiversidad, ubicación geográfica, presencia de lagos y ríos y porque es un espacio para el desarrollo económico de las fronteras. El motivo para desarrollar este artículo es, a razón de que en Brasil y Perú se desenvuelve una serie de dinámicas fronterizas sean territoriales, sociales, comerciales y económicas. El artículo tiene por objetivo analizar las regiones limítrofes entre Perú y Brasil como un espacio con características distintivas, lo que coadyuva a determinar posibles acciones futuras en la integración fronteriza. El estudio es descriptivo, de abordaje cualitativo basado en la revisión documental y cuantitativa de fuentes de secundarias. Se concluye en la necesidad de usar estrategias políticas, económicas, sociales pensadas de abajo-arriba que incorpore a diferentes actores multinivel, así como fortalecer los proyectos ya existentes que permitan

* Maestría (c) en Política Científica y Tecnológica por la Universidade Estadual de Campinas (UNICAMP, Brasil). Especialista en Estrategia y Relaciones Internacionales Contemporáneas por la Universidade Federal do Rio Grande do Sul (UFRGS), Brasil, 2021. Magíster en Gerencia Social por la PUCP. Politóloga de la Universidad Nacional Mayor de San Marcos. E-mail: itala.laurente@gmail.com

Filiación: Universidade Estadual de Campinas, UNICAMP, Universidade Federal do Rio Grande do Sul, UFRGS

(iD) https://orcid.org/0000-0001-9836-7051

** Profesor titular del Departamento de Economía y Relaciones Internacionales de la Universidade Federal do Rio Grande do Sul, UFRGS, Brasil. Doctor en Economía Política por la UVQY - Université de Versailles - SaintQuentin-en-Yvelines, Francia. Magíster en Economía Rural por la UFRGS, Brasil, 1997. Bachiller en Ciencias Económicas por la UFRGS, Brasil. E-mail: edu_292000@yahoo.com.br Filiación: Universidade Federal do Rio Grande do Sul, UFRGS

(iD) https://orcid.org/0000-0001-8311-7287 
la fluidez del comercio y mercado de productos tanto peruanos como brasileños a través de las fronteras, finalmente, reforzar la integración y cooperación entre fronteras para combatir actividades ilícitas y el mejoramiento del desarrollo de esas regiones.

Palabras clave: fronteras, cooperación transfronteriza, integración, Brasil, Perú.

Brazil and Peru borders, space for integration and cooperation

\section{Abstract}

Borders are spaces where relations between the local population and the different levels of government, whether national or subnational, are condensed. Therefore, it is relevant to create border areas of peace and sustainable development, based on regional cohesion, social integration, and territoriality, which contributes to the reduction of tensions between countries and consolidates the processes of integration and continuous cooperation. Particularly, the borders of Brazil and Peru have a strategic relevance due to their biodiversity, geographic location, presence of lakes and rivers and because it is a space for the economic development. The reason for developing this article is that Brazil and Peru have a series of border dynamics, whether territorial, social, commercial and economic. The objective of the article is to analyze the border regions between Peru and Brazil as a space with distinctive characteristics, which helps to determine possible future actions in border integration. The study is descriptive, with a qualitative approach based on documentary and quantitative review of secondary sources. It concludes that there is a need to use political, economic, social and bottom-up strategies that incorporate different multilevel actors, as well as to strengthen existing projects that allow the flow of trade and market of both Peruvian and Brazilian products across the borders, and finally, to strengthen integration and cooperation between borders to combat illegal activities and improve the development of these regions.

Keywords: Borders, cross-border cooperation, integration, Brazil, Peru.

\section{Introducción}

Las fronteras permiten interacciones entre las regiones y posibilitan vínculos entre sociedades vecinas, se convierten en un espacio de socialización donde se desarrollan costumbres y prácticas diferenciadas, asimismo, se intensifica el diálogo entre diferentes actores, agentes económicos e instituciones que operan de uno y otro lado de la frontera.

La cooperación transfronteriza entre regiones puede ser un elemento catalizador del desarrollo y un instrumento económico. Es un proceso que requiere la construcción de directrices y el planteamiento de marcos de referencia institucional y de la participación de múltiples actores de los diferentes niveles de gobierno. Desde un aspecto de fronteras locales, la cooperación transfronteriza, además de colaborar con 
la multiplicidad participativa, también coadyuva a establecer soluciones descentralizadas en asuntos como servicios públicos o gestión de políticas públicas.

A cooperação transfronteiriça se vê favorecida quando existem três condiçóes fundamentais: que os territórios compreendidos participem de processo de conectividade física, que se conte com vontade e acordo político de alto nível entre os países envolvidos que permita se materializar em algum marco institucional de ordenação de suas relaçóes e, por último, que se reconheça a participaçấo dos governos subnacionais fronteiriços - na qualidade de articuladores dos atores locais -, como instância institucional fundamental para uma positiva governabilidade transfronteiriça (Rhi-Sausai y Oddone, 2012, p.154).

Así, al ser las fronteras consideradas como un instrumento de socialización y desarrollo, esta se refuerza con la integración y cooperación transfronteriza, sobre todo, de los gobiernos subnacionales ubicados en frontera. Particularmente Brasil y Perú comparten frontera territorial de aproximadamente $2995 \mathrm{~km}$ y tiene una relevancia estratégica a razón de la biodiversidad, ubicación geográfica y por acceso a los océanos Pacífico y Atlántico, convirtiéndose en espacios para el desarrollo económico y social.

Teniendo esto presente, el motivo para desarrollar este artículo es, debido a que, en Latinoamérica se desenvuelve una serie de dinámicas fronterizas, sean territoriales, sociales, comerciales y económicas, es así que las fronteras entre Brasil y Perú no están exentas de ello. Por esta razón, como refiere Oddone (2014), es relevante la integración, pues contribuye al abordaje de los pueblos, la disminución de los efectos de división territorial, la intensificación de los vínculos, la mejora de redes, de diseño de ejes y corredores, la autonomía de los gobiernos subnacionales, la mejora de procesos comerciales, la adaptación de políticas, la satisfacción de demandas sociales locales, la mejora del proceso de descentralización y la gobernanza horizontal.

Para tal fin, el artículo tiene por objetivo analizar las regiones limítrofes entre Perú y Brasil como un espacio con características distintivas, lo que contribuye a determinar posibles acciones futuras en la integración fronteriza. El texto, además de la introducción, aborda las nociones de territorio, región y fronteras; incluye las características de los estados brasileños y regiones peruanas en la zona de frontera; también, los espacios de cooperación e integración fronteriza y, por último, las consideraciones finales.

\section{Territorio, región y fronteras}

La idea de territorio está relacionada con la palabra poder desde una mirada no solo de dominación, sino de apropiación de sociedad y espacio. El territorio es diverso y complejo, presenta multiplicidad con sobreposición de jurisdicciones y de territoria- 
lidad con relaciones económicas y culturales. Asimismo, el territorio es «un espacio social, históricamente producido y organizado, que traspasa relaciones de poder, por redes y por identidades que están en constante transformación en el tiempo» ${ }^{1}$ (De Souza, 2013, p. 65).

Un aspecto relacionado a territorio es la fluidez territorial — la cual es la calidad del movimiento asociada a la infraestructura —, ese movimiento está supeditado a las condiciones materiales e inmateriales que aseguran la circulación de personas, de servicios, ideas e informaciones, entre otros. Lo que incentiva la integración regional, ejemplo de ello, fue la Iniciativa para la Integración de la Infraestructura Regional Sudamericana (IIRSA), propuesta que tuvo el propósito de lograr la integración política, social, cultural y económica en Sudamérica a través del desarrollo en el transporte, energía y telecomunicaciones (De Souza, 2013).

Entendemos el concepto de región como un territorio que conforma una unidad homogénea con elementos históricos, geográficos, culturales, lingüísticos, entre otros. De Souza (2013) señala que la sociedad determina ese espacio geográfico llamado territorio y crea una identidad que implica lo que es territorialidad. Asimismo, Haesbaert (2004) considera que la región comprende la vivencia real de una sociedad o individuo creándose una idea de pertenencia y de identidad. Por tal motivo, entendemos que los conceptos de territorio y región están vinculados al movimiento de construcción, deconstrucción y reconstrucción de las regiones.

En relación con las fronteras, estas no solo deben ser entendidas como una organización territorial, también son espacios donde se concentran las relaciones entre la población local y los diferentes niveles de gobierno sea nacional o subnacional, además, constituyen diferentes realidades políticas, sociales, culturales y económicas (Oddone, 2014). También, las fronteras unen pueblos, siendo espacios comunes donde las personas realizan trabajos cotidianos, estudios, actividades de ocio y convivencia familiar (Vargas, 2017). Por eso, como menciona Oddone (2014) es relevante la creación de áreas fronterizas de paz y desarrollo sustentable, con base en la cooperación, cohesión social y territorialidad, lo que contribuye a la disminución de las tensiones entre los países y consolida los procesos de integración continua.

\subsection{Formación de fronteras latinoamericanas}

Después de la independencia de países latinoamericanos, durante el siglo XIX, varias de las demarcaciones fronterizas se ampararon en el uti possidetis ${ }^{2}$. La formación

\footnotetext{
1 Traducción propia.

2 «El alcance del uti possidetis se refiere al territorio que debe pertenecer a cada nación según las demarcaciones que estaban vigentes en 1810 [...] Este fue aceptado a raíz de la independencia por los pueblos americanos en las cons-
} 
de los Estados en Latinoamérica simbolizó un proceso de independencia y construcción de fronteras, suscitándose una cantidad de conflictos en esta zona, incluso algunas continúan. La idea de que las fronteras son zonas de nadie o despobladas fue cambiando con el paso del tiempo, debido a que los países comenzaron a concebirlas como áreas estratégicas por ser zonas para la experimentación social, integración regional y relaciones transfronterizas.

En el caso de Latinoamérica, aún existen disputas fronterizas entre los cuales tenemos: Venezuela y Guyana, por el área de Esequiba (minerales, flora y recursos energéticos); Costa Rica y Nicaragua, tienen una disputa por la isla fluvial localizada en el lago Los Portillos; Nicaragua y Colombia, disputas por límites marítimos; Guatemala y Belice, por $11030 \mathrm{~km}^{2}$; Honduras y El Salvador por la isla Conejo, localizada en el golfo de Fonseca; Honduras y Nicaragua, tienen una disputa marítima en el paralelo 15. En América del Sur, Chile y Bolivia tenía dos acciones judiciales, una para obtener el acceso al mar3 y otra por el uso de las aguas del río Silala que Chile utiliza para la minería; Chile y Perú, presenta impases por los límites y recursos marítimos (este caso se resolvió en el Tribunal de La Haya); Guyana y Surinam, por el área entre los ríos Boven-Corantin y Koetar por el petróleo y gas natural; Venezuela y Colombia, por el golfo de Venezuela; Bolivia y Brasil, disputa territorial por la isla fluvial localizada en el río Mamoré (Luján, 2017).

Una manera de mejorar los problemas fronterizos es a través de las relaciones bilaterales. Sudamérica, al final de la década de 1990, realizó eventos, acuerdos y organizaciones en la región4. Eso continuó en el siglo XXI5 como actividades macro para fortalecer la cooperación entre actores locales subnacionales, legislación fronteriza, control de la gobernanza fronteriza, políticas públicas conjuntas, erradicación del hambre, lucha contra las desigualdades sociales, universalización de la salud pública y educación, libre circulación, igualdad de derechos, entre otros. Todas estas iniciativas pretenden reforzar la integración regional y la adaptación de las características que puedan surgir en una zona fronteriza como los es la interculturalidad, discriminación, contrabando, tráfico de personas, entre otros (Neto y Penha, 2016).

\footnotetext{
tituciones políticas, declaraciones de sus gobiernos y escritos" (Porras Barrenechea, 1926).

3 En 2018, este conflicto fue resuelto por la Corte Internacional de Justicia, determinándose que Chile no contrajo obligación de negociar acceso soberano al mar con Bolivia.

4 Creación del Protocolo de Ushuaia (1998) y la Declaración Política del Mercosur, Bolivia y Chile como zona de paz (1999).

5 Tránsito de Vecindad entre Estados del Mercosur y el libre comercio de personas en ciudades gemelas, Foro Consultivo de Municipios (2004), el Fondo para la Convergencia Estructural de Mercosur (2004), el proyecto Nro. 10/07 de fortalecimiento de las comunidades locales en la frontera de Uruguay, Argentina y Brasil para fortalecer las comunidades locales, el Plan Estratégico de Acción Social, Plan de Acción para conformación del Estatuto de Ciudadanía, y la Carta de Ciudadanía del Mercosur, entre otros.
} 
En este contexto, los gobiernos subnacionales contribuyen a la preservación ambiental, a la protección de los bienes históricos y culturales, al desarrollo local en salud y educación, a la protección de infraestructura crítica, la movilidad de personas, la elaboración de programas sociales, entre otros. Desde el punto de vista geopolítico, existe ciertas características que no permiten la integración en Sudamérica como las rivalidades regionales, la baja integración por no tener vías de comunicación, y una baja cooperación militar sobre todo en el control de las fronteras, infraestructura compartida y disponible.

\section{Estados brasileńos y regiones peruanas fronterizas}

\subsection{Frontera Brasil y Perú}

La integración de las fronteras Brasil - Perú data desde 1851, con el convenio fluvial denominado Convención Especial de Comercio, Navegación y Límites, firmada por Bartolomé Herrera (Perú) y Duarte da Ponte Ribeiro (Brasil) constituyéndose el límite de Tabatinga en el Amazonas y la confluencia del río Apaporis en Japurá. Si bien se establecían límites de frontera el principal interés era la libre navegación en el Amazonas (Porras Barrenechea, 1926; Jorge, 1999).

En 1866, los comisionados de ambos países resolvieron fijar los hitos fronterizos, «Comenzando por la boca del Apaporis, siguiendo por el río Putumayo, donde se convinieron algunos cambios de territorios, y terminando en 1874 con la exploración del río Yavarí, cuyo nacimiento fue fijado en el grado $7^{\circ} 1^{\prime} 17^{\prime \prime} 5$ latitud Sur y 7408'27"07 de longitud Oeste». Posteriormente, las fronteras de Brasil y Perú presentaron cierta conflictividad en la zona denominada Alto Juruá, por eso, en julio de 1904, se realizó ciertos acuerdos entre los dos países (Porras Barrenechea, 1926).

Sin embargo, el tratado fue firmado cinco años después, el 8 de setiembre de 1909, entre Barão do Rio Branco e Hernán Velarde. Brasil acordó ceder parte de Acre al Perú $\left(39000 \mathrm{~km}^{2}\right)$, y este a su vez reconoció $403000 \mathrm{~km}^{2}$ a Brasil en territorio amazónico (Porras Barrenechea, 1926; Jorge, 1999). Ya para 1925, Brasil, Perú y Colombia firmaron el Acta de Washington reconociendo la línea Apaporis - Tabatinga como constitutiva de la frontera (Vargas, 2017).

Cabe destacar que, como parte de las negociaciones entre países fronterizos, se realizó el Tratado de 1907, la transcendencia del mismos es porque fijó una línea limítrofe entre territorios disputados por cuatro países, esto es, Perú, Ecuador, Colombia y Venezuela, siendo relevante la participación brasileña a través de Rio Branco (Vargas, 2017). 
Por otro lado, n la triple frontera entre Brasil, Perú y Colombia — bajo la idea de la seguridad nacional y la soberanía - se realizaron políticas públicas no incluyentes que reforzaban las diferencias entre las distintas amazonias, lo que originó estados unidimensionales, asimismo, esta zona tripartita fue dejada de lado en relación con los polos económicos y políticos de los países. Ya para la década del sesenta y setenta, la política brasileńa estuvo orientada a fortalecer la frontera agrícola y la colonización, con un discurso de «revolución verde» el que propició la deforestación de la Amazonía y el uso de agroquímicos con el fin de una mayor productividad. No obstante, para fines del siglo XX, el discurso ambientalista dio pase a políticas de protección del medio ambiente, así como la creación de ministerios y oficinas, viéndose esto reflejado en las políticas fronterizas (Zárate Botía, 2017).

Actualmente, Brasil y Perú tienen varios aspectos que determinan la importancia de estas fronteras, pues constituyen nudos claves de integración física, además, tienen $2995 \mathrm{~km}$ de frontera compartida situada entre las once mayores fronteras del mundo, con presencia de recursos naturales y Amazonía, y $2003 \mathrm{~km}$ son delimitados por aguas, entre ríos y canales. Asimismo, tienen una frontera tripartita con Colombia y otra con Bolivia. Los estados fronterizos brasileños son Amazonas y Acre, y por el lado peruano se encuentran las regiones de Madre de Dios, Ucayali y Loreto.

Podemos decir que, a lo largo de la historia, la frontera de Brasil con Perú se determinó a través de convenios y acuerdos fronterizos, sin presencia de enfrentamientos bélicos. Se caracteriza por ser una frontera amazónica con gran presencia de agua y biodiversidad. A pesar de ciertas políticas públicas que promovían la protección y preservación de la Amazonía, estas fronteras han sido tratadas de manera marginal, colocándolas como meros límites de la soberanía de un país, lo que propicia poca integración regional y falta de participación multinivel por parte de los gobiernos subnacionales y locales, así como políticas top-down que obstaculizan las demandas de la población que vive en frontera y disminuye la posibilidad de tener áreas de convergencia económicas e institucionales.

Ambos países tienen políticas, estrategias y acciones fronterizas establecidas. La Constitución Brasileńa establece la integración en Latinoamérica, particularmente en el artículo $4^{\circ}$ señala que "A República Federativa do Brasil buscará a integração econômica, política, social e cultural dos povos da América Latina, visando à formação de uma comunidade latino-americana de naçôes» (Constituiçâa da República Federativa do Brasil, 1988). Asimismo, entre las acciones vinculadas a las cuestiones fronterizas se encuentran la Política Nacional de Defensa (2013) y la Estrategia Nacional de Defensa (END) que colocan la Amazonía como prioridades por los recursos minerales y biodiversidad. Otro tipo de acciones son el Plan 
Estratégico de Fronteras ${ }^{6}$, la directriz para las actividades del Ejército Brasileño en el área Internacional (DAE-BAI), las fronteras vivas a través de los pelotones de frontera $^{7}$ en Acre y Amazonas (brigada de São Gabriel da Cachoeira y en Tefé), y el Sistema Integrado de Monitoreo de Fronteras (SISFRON) — que tiene como principal meta controlar los ilícitos transfronterizos, aumentar la cooperación y la diplomacia militar brasileña (Landim, 2015).

En el Perú, su Constitución, en el artículo 44 menciona que es deber del Estado establecer y ejecutar la política de fronteras y promover la integración, particularmente en Latinoamérica, bien como el desarrollo y la cohesión de las áreas de fronteras, de acuerdo con la política externa (Constitución Política del Perú, 1993). Además, la Política Nacional de Seguridad y Defensa Peruana promueve el establecimiento y consolidación de las fronteras vivas como polos auténticos de desarrollo ${ }^{8}$ (Presidencia del Consejo de Ministros, 20017). Posee la Estrategia Nacional de Desarrollo e Integración Fronteriza 2007-2021 que promueve el desarrollo sustentable, incentiva la presencia del Estado, la igualdad de oportunidades, el respeto por el multiculturalismo, concordar las acciones estatales con la sociedad y las organizaciones representativas en las fronteras para promover el desarrollo sostenible y la presencia del Estado en el proceso de integración fronteriza, la soberanía y la seguridad nacional.

\subsubsection{Características demográficas, socioeconómicas y dinámica de movilidad de las zonas fronterizas de Brasil y Perú}

La relevancia de los datos demográficos y socioeconómicos es que registran cambios en la distribución y composición de la población, así como consideran información sobre el universo y características de la población, aspectos significativos que pueden coadyuvar a la toma de decisiones estratégicas y en materia de políticas públicas.

Algunos datos preliminares, basado en información de la Comisión Económica para América Latina y el Caribe (Cepal, s.f.a, s.f.b) —organización que elabora proyecciones de datos sociodemográficos— señala que, para el periodo 2020-2025 se estima que en Brasil la tasa anual de crecimiento poblacional es de 0,6\% (en urbano 0,9\% y rural $-1,1 \%$ ), tasa bruta de natalidad de $12,8 \%$, tasa bruta de mortalidad de $6,8 \%$ con esperanza de vida de 77 años (mujeres 80 años y varones 73 años). Además, la Cepal muestra que, en 2019, Brasil tuvo una tasa de desempleo de 11,9\%, con salario medio real anual de 110,3, con 19,2\% de personas en situación de pobreza

\footnotetext{
6 Tiene como objetivo la implementación de proyectos estructurantes para el fortalecimiento de la presencia estatal en la región de frontera y la actuación integrada de los órganos de seguridad pública y de las Fuerzas Armadas.

7 Los pelotones especiales de frontera son parte del Ejército Brasileńo, que cuenta con aproximadamente setenta efectivos militares. Existen veinticuatro pelones de fronteras.

8 Decreto Supremo No 027-2007-PCM, artículo 2, numeral 12.3.
} 
( $17,2 \%$ urbano y $32 \%$ rural) y $5,5 \%$ en extrema pobreza ( $4,3 \%$ urbano y $13,4 \%$ rural).

Para el caso de Perú, la tasa anual de crecimiento poblacional es de $0,9 \%$ (en urbano $1,4 \%$ y rural $-0,1 \%)$, tasa bruta de natalidad de $16,9 \%$, tasa bruta de mortalidad de 5,9\%, con esperanza de vida de 77 años (mujeres 80 ańos y hombres 75 años). Asimismo, en 2019, Perú tuvo una tasa de desempleo de 3,9\%, con salario medio real anual de 126,8 , con un $15,4 \%$ de personas en situación de pobreza ( $11 \%$ urbano y $31,4 \%$ rural), y de $3 \%$ en extrema pobreza ( $1,2 \%$ urbano y $9,7 \%$ rural) (Cepal, s.f.).

Específicamente, en la zona fronteriza brasileńa-peruana, como muestra la tabla 1, en Perú el 23,1\% de la población se encuentra entre los 0 a 9 ańos $(9,6 \%$ hombres y $9,4 \%$ mujeres) y $19 \%$ entre 10 a 19 años ( $9,6 \%$ hombres y $9,4 \%$ mujeres). En Brasil $22,2 \%$ tiene entre 10 a 19 ańos (11,2\% hombres y $11 \%$ mujeres) seguido de la población entre 0 a 9 ańos (11,1\% hombres y 10,6\% mujeres). Estos datos muestran que las regiones peruanas, así como los estados brasileños fronterizos presentan una población mayoritariamente joven, a razón de que la distribución de población oscila entre los 0 a 19 años.

Tabla 1. Distribución poblacional fronteriza entre Perú y Brasil, por edad y sexo

\begin{tabular}{|c|c|c|c|c|}
\hline \multirow[b]{2}{*}{ Edades } & \multicolumn{2}{|c|}{ Perú } & \multicolumn{2}{|c|}{ Brasil } \\
\hline & Hombres & Mujeres & Hombres & Mujeres \\
\hline De 0 a 9 años & $11,8 \%$ & $11,3 \%$ & $11,1 \%$ & $10,6 \%$ \\
\hline De 10 a 19 años & $9,6 \%$ & $9,4 \%$ & $11,2 \%$ & $11,0 \%$ \\
\hline De 20 a 29 años & $8,0 \%$ & $8,6 \%$ & $9,4 \%$ & $9,5 \%$ \\
\hline De 30 a 39 años & $7,4 \%$ & $7,3 \%$ & $7,3 \%$ & $7,4 \%$ \\
\hline De 40 a 49 años & $5,8 \%$ & $5,3 \%$ & $5,0 \%$ & $4,9 \%$ \\
\hline De 50 a 59 años & $4,4 \%$ & $3,7 \%$ & $3,2 \%$ & $3,2 \%$ \\
\hline De 60 a 69 años & $2,6 \%$ & $2,0 \%$ & $1,8 \%$ & $1,8 \%$ \\
\hline De 70 a 79 años & $1,1 \%$ & $0,9 \%$ & $0,9 \%$ & $0,9 \%$ \\
\hline De 80 a más años & $0,4 \%$ & $0,4 \%$ & $0,4 \%$ & $0,4 \%$ \\
\hline Total & $51,0 \%$ & $49,0 \%$ & $50,3 \%$ & $49,7 \%$ \\
\hline
\end{tabular}

Fuentes: Instituto Nacional de Estadística e Informática [INEI], 2017a, 2017b, 2017c; Instituto Brasileiro de Geografia e Estatística, 2010a, 2010b. Elaboración propia. 
Por otra parte, considerando la variación de la población urbano y rural. En el caso de Perú, se tomó como fuente los censos de 2007 y 2017, donde la variación de población rural disminuyó en -18\% (85953 habitantes), mientras que la urbana aumentó en 18\% (173 546). Para el caso de Brasil, se consideró los censos nacionales de 2000 y 2010, la población rural aumentó en 4\% (333 722 habitantes), en tanto que la población urbana en 33\% (813 461), con una variación de 25\%. Estos datos hallados indican que la población en las regiones fronterizas peruanas aumentó $6 \%$ en diez años, mientras que en los estados fronterizos brasileños aumentó en un 25\% en diez años.

Tabla 2. Variación de la población urbano/rural de las regiones fronterizas*

\begin{tabular}{|c|c|c|c|c|c|c|c|c|}
\hline & \multicolumn{4}{|c|}{ Perú } & \multicolumn{4}{|c|}{ Brasil } \\
\hline & $\begin{array}{l}\text { Censo } \\
2007\end{array}$ & $\begin{array}{l}\text { Censo } \\
2017\end{array}$ & $\begin{array}{c}\text { Var 2007- } \\
2017\end{array}$ & $\begin{array}{l}\text { Var \% } \\
2007- \\
2017\end{array}$ & $\begin{array}{l}\text { Censo } \\
2000\end{array}$ & $\begin{array}{l}\text { Censo } \\
2010\end{array}$ & $\begin{array}{c}\text { Var } \\
2000-2010\end{array}$ & $\begin{array}{l}\text { Var \% } \\
2000- \\
2010\end{array}$ \\
\hline Rural & 481362 & 395409 & -85953 & $-18 \%$ & 896003 & 929775 & 33772 & $4 \%$ \\
\hline Urbano & 952084 & 1125630 & 173546 & $18 \%$ & 2474308 & 3287769 & 813.461 & $33 \%$ \\
\hline Total & 1433446 & 1521039 & 87593 & $6 \%$ & 3370311 & 4217544 & 847233 & $25 \%$ \\
\hline
\end{tabular}

*Considera los estados brasileños de Amazonas y Acre, y las regiones peruanas de Loreto, Ucayali y Madre de Dios. Fuente: INEI, 2017a, 2017b, 2017c; Instituto Brasileiro de Geografia e Estatística, 2010a, 2010b. Elaboración propia.

Los indicadores sociales muestran que la mayor población fronteriza se encuentra en el estado brasileńo de Amazonas (3 483 985,00), seguido de Loreto (883 510,00) y Acre $(733559,00)$. Sin embargo, la mayor densidad poblacional se encuentra en la región de Ucayali $(4,86)$ seguido de Acre $(4,47)$. El mayor índice de desarrollo humano (IDH) se encuentra en Brasil, en los estados de Amazonas $(0,674)$ y Acre $(0,663)$, las regiones peruanas tienen índices más bajos. 
Tabla 3. Comparativo de indicadores sociales entre los estados fronterizos brasileños y las regiones peruanas

\begin{tabular}{llcccc}
\hline País & $\begin{array}{l}\text { Región } \\
\text { /Estado }\end{array}$ & $\begin{array}{c}\text { Población } \\
\text { (último censo) }\end{array}$ & $\begin{array}{c}\text { Área } \\
\mathrm{km}^{2}\end{array}$ & $\begin{array}{c}\text { Densidad } \\
\text { poblacional }\end{array}$ & $\begin{array}{c}\text { Índice de Desarrollo } \\
\text { Humano (IDH) }\end{array}$ \\
\hline Perú & Loreto & 883510,00 & 368851,00 & 2,40 & 0,398 \\
Perú & Madre de Dios & 141070,00 & 85301,00 & 1,65 & 0,558 \\
Perú & Ucayali & 496459,00 & 102199,00 & 4,86 & 0,432 \\
Brasil & Acre & 733559,00 & 164173,43 & 4,47 & 0,663 \\
Brasil & Amazonas & 3483985,00 & 1559167,88 & 2,23 & 0,674 \\
\hline
\end{tabular}

*Se consideró el último censo de ambos países, 2017 Perú y 2010 Brasil.

Fuente: Población/Área/Densidad Poblacional Loreto: INEI, 2017a. Población/Área/Densidad Poblacional Madre de Dios: INEI, 2017b. Población/Área/Densidad Poblacional Ucayali: INEI, 2017b. Datos de Acre: IBGE, $2010 \mathrm{a}$. Datos de Amazonas: IBGE, 2010b. Elaboración propia.

Asimismo, los indicadores económicos señalan que la mayor tasa de desempleo se encuentra en Amazonas (9,54\%) seguido de Acre (7,54\%), mientras que en Perú la tasa de desempleo es más baja, Ucayali $(2,7 \%)$, Loreto $(2,3 \%)$ y Madre de Dios $(1,5 \%)$. Eso también se refleja en el ingreso promedio en dólares, ubicándose el mayor ingreso promedio en la región peruana de Madre de Dios (450 USD), seguido de Loreto (332,84 USD) y Ucayali (317,42 USD), en cambio Brasil el ingreso promedio es mayor, siendo en Acre de 156,41 USD y en Amazonas de 147,99 USD.

Con relación a la inversión pública, el presupuesto público per cápita mensual más alto se encuentra en la región de Acre con 1.458 USD, seguido por Amazonas con 773 USD, Madre de Dios con 178 USD, Loreto con 96 USD y el último Ucayali con 93 USD. El IDH es liderado por Amazonas $(0,674)$ seguido de Acre $(0,663)$, Madre de Dios $(0,558)$, Ucayali $(0,432)$ y Loreto $(0,398)$. Una forma de ver cómo es la economía formal en la zona, es a través de la bancarización, los datos muestran que existe una mayor inserción de bancarización en el estado de Amazonas con 207 agencias, muy por encima de las demás regiones (por ejemplo, Acre con 56 y Loreto 53 agencias).

Estos resultados indican que la mayor tasa de desempleo se encuentra en los estados fronterizos brasileños. Por otro parte, las regiones peruanas fronterizas tienen mayor ingreso promedio en dólares. Sin embargo, en indicadores como la inversión pública y el presupuesto público per cápita mensual, el IDH y la inserción de bancarización son mejores en los estados brasileños que en las regiones peruanas. 
Tabla 4. Comparativo de indicadores económicos entre los estados fronterizos brasileńos y las regiones peruanas

\begin{tabular}{llcccc}
\hline País & $\begin{array}{l}\text { Región } \\
\text { /Estado }\end{array}$ & $\begin{array}{c}\text { Agencias } \\
\text { financieras }\end{array}$ & $\begin{array}{c}\text { Presupuesto } \\
\text { público per cápita } \\
\text { mensual (USD) }\end{array}$ & $\begin{array}{c}\text { Tasa } \\
\text { desempleo }\end{array}$ & $\begin{array}{c}\text { Ingreso } \\
\text { promedio } \\
\text { (USD) }\end{array}$ \\
\hline Perú & Loreto & 53 & 96 & 2,30 & 332,84 \\
Perú & Madre de Dios & 23 & 178 & 1,50 & 450,00 \\
Perú & Ucayali & 49 & 93 & 2,70 & 317,42 \\
Brasil & Acre & 56 & 1.458 & 7,54 & 156,41 \\
Brasil & Amazonas & 207 & 773 & 9,54 & 147,99 \\
\hline
\end{tabular}

Fuente: Información extraída de las Agencias Financieras Loreto: Banco Central del Perú [BCRP], 2018. Agencias Financieras Madre de Dios: BCRP, 2018. Agencias Financieras Ucayali: BCRP, 2018. Ranking/Presupuesto per capita/Ingreso Promedio Loreto: Instituto Peruano de Economía [Incore], 2020. Ranking/Presupuesto per cápita/ Ingreso Promedio Madre de Dios: IPE, 2020. Ranking/Presupuesto per cápita/Ingreso Promedio Ucayali: IPE, 2020. Elaboración propia.

Las características particulares de los espacios fronterizos influyen en la organización y dinámica social, desde los aspectos demográficos, sociales, económicos hasta las dinámicas de movilidad en fronteras sean turísticas o no, esto permite reflexionar sobre el funcionamiento e identificación en las fronteras.

En referencia a la movilidad en la frontera brasileña-peruana, la información de movilidad turística mostró que, en el Perú, la región de Loreto presentó turistas nacionales en $2,5 \%$ del total, de estos, $45 \%$ son loretanos. El transporte más usado fue el avión (39\%) y medios fluviales (32\%). El ingreso de extranjeros hacia la región Loreto fue de 589 (Comisión de Promoción del Perú para la Exportación y el Turismo, 2018a).

Para la región de Madre de Dios, el 0,7\% son turistas nacionales la mayoría provenientes de Lima, el transporte más usado es el bus (61\%) seguido del aéreo (22\%). El puesto de control con mayor movimiento de personas en frontera se encuentra en la localidad de Ińapari, ubicado en la región de Madre de Dios (Comisión de Promoción del Perú para la Exportación y el Turismo, 2018b). En 2017, el perfil del turista que llega a la región de Ucayali, es $1.7 \%$ turistas peruanos en su mayoría provenientes de lima (67\%), trabajadores independientes $29 \%$, viajando por negocios $(35 \%)$ o por recreación $(31 \%)$ y se transportan en bus interprovincial (45\%) o avión (38\%) (Comisión de Promoción del Perú para la Exportación y el Turismo, 2018c). 
Por el contrario, en 2018, Brasil presentó dinámicas de movilidad diferentes. La llegada de turistas por el estado de Acre fue de 31537, de ese total, casi el $95 \%$ fueron sudamericanos. De los sudamericanos identificados, casi $50 \%$ fueron peruanos (Ministério de Turismo do Brasil, 2018). En cambio, para el estado de Amazonas, la llegada de los turistas peruanos es poca (1804) en comparación con el total (36 064) de desplazamientos en frontera (Ministério de Turismo do Brasil, 2012).

\subsubsection{Actividades ilícitas e inmigración en las fronteras}

Actividades ilícitas

Brasil se ha convertido en un territorio de transbordo de cocaína boliviana, colombiana y peruana con destino a Europa, es usado por traficantes como estación de paso para transbordos aéreos de narcóticos entre Perú y Colombia, lo que produce un incremento de la violencia relacionada con las drogas y el contrabando de armas. El producto de los narcóticos ilícitos comúnmente se lava por medio del sistema financiero, por esto, hay presencia de actividad financiera ilícita en el sector de la triple frontera sea con Colombia o Bolivia (CIA, 2021).

En la actualidad, Perú es ahora el segundo productor mundial de hoja de coca, y la producción colombiana supera a la peruana. El cultivo de hoja de coca en Perú se estimó en 44000 hectáreas en 2016, siendo una disminución del 16\% con relación a 2015. La cocaína terminada se envía a partir de los puertos del Pacífico al mercado de drogas, no obstante, aún se traslada cantidades grandes de cocaína base y terminada a Brasil, Chile, Argentina y Bolivia para su uso en la región o como transbordo a Europa y África (CIA, 2021).

Salisbury y Fagan (2013) detallan que si bien las zonas fronterizas entre la región de Ucayali y el estado de Acre, se encuentran en un área considera biodiversa y biocultural $^{9}$, es a partir de 1980, que llegaron cocaleros a la zona fronteriza de Ucayali con el fin de cultivar y cosechar la hoja de coca, siendo la ciudad de Purús una ruta de transporte hacia Brasil. Desde entonces, a partir de la década de 1980, los cultivos de hoja de coca han aumentado, dependiendo de las rutas de transporte tradicionales como lagos o ríos. Esta dinámica conllevó paulatinamente a impactos sociales y culturales por la presencia de narcotráfico, asimismo, se generó conexiones entre

\footnotetext{
9 La zona fronteriza de Ucayali se caracteriza por la presencia de culturas diversas, desde shipibo-conibos, asháninkas, aguarunas, mestizos, brasileńos, así como madereros, mineros y cocaleros, donde la economía gira en torno a la agricultura de subsistencia y extracción maderera. Asimismo, la ciudad de Purús, donde se encuentra un Parque Nacional Alto Purús, presenta limitaciones económicas y se vive principalmente de la caza, pesa, horticultura y explotación de la madera, y posee una mayor diversidad cultural (Cashinahua, Sharanahua, Culina, Mastanahua, Amahuaca, Chaninahua, Asháninka y Yine), el resto de la población es mestiza, brasileños mestizos o brasileños (Salisbury y Fagan, 2013).
} 
habitantes, madereros y cocaleros, siendo esta zona entrada para el contrabando y ruta del narcotráfico.

Ante el aumento progresivo de la producción de cultivo de hoja de coca y una manera de evitar el ingreso del narcotráfico y el tráfico internacional de drogas en territorio brasileño, Brasil y Perú firmaron un acuerdo entre gobiernos denominado Cooperación en Materia de Protección y Vigilancia de la Amazonía con el fin de compartir información obtenida del Sistema de Protección/Vigilancia de la Amazonía (SIPAM/SIVAM) y así realizar controles y vigilancia en los espacios aéreos fronterizos, dicho acuerdo también permite capacitaciones y proyectos conjuntos. Además, ambos países tuvieron operaciones en conjunto como la operación Pebra (2003), Cobra (2000), Trapecio (2011), Trapecio II (2012), Trapecio III (2013) y es en esta última operación que se logró destruir veintiocho laboratorios que procesaban droga que tenían como destino ingresar por Tabatinga en el estado de Amazonas (Dias, 2015).

En consecuencia, las fronteras se encuentran en una situación aún vulnerable. Por ejemplo, en la frontera tripartita —entre Brasil, Perú y Colombia— las políticas de centro-periferia, sumado a un Estado precario, presencia de pobreza, narcotráfico y crimen organizado, así como políticas de seguridad que no colaboran con estrategias conjuntas entre países (García Pinzón, 2018), muestra la poca presencia de la cooperación transfronteriza, la paradiplomacia y políticas públicas bottom-up.

Inmigración en fronteras

De manera general, los gobiernos de Perú y Brasil tienen acuerdos comunitarios como el Mercado Común del Sur (Mercosur) que establece residencia temporaria, así como reconoce derechos civiles, sociales y económicos a los inmigrantes de países que son parte del Mercosur. Asimismo, tienen un convenio bilateral suscrito en 2004 para dar facilidades de ingreso y tránsito de sus nacionales a sus territorios.

A razón de los conflictos agrarios y la situación económica, la inmigración peruana fue principalmente masculina, quienes se movilizaban a ciudades de Ucayali o Iquitos, para posteriormente cruzar la Amazonía brasileña primordialmente hacia el estado de Amazonas. A partir de 1990, la inmigración femenina peruana aumentó en Brasil, siendo principalmente esposas de inmigrantes peruanos que ya vivían en el país (Chiarello, 2011). Según el Centro Latinoamericano y Caribeño de Demografía (Celade) de la Cepal (2012), la mayoría de los inmigrantes peruanos en Brasil oscilan entre los 35 y 39 años (12,6\%), seguido de 30 a 34 años (11,9\%), y 25 a 29 años $(10,5 \%)$, son predominantemente hombres $(61,5 \%)$, tiene como principales actividades económicas el comercio, reparaciones, hoteles $(34,3 \%)$ y servicios comunales, sociales y personales $(33,3 \%)$. 
Con el paso del tiempo, las regiones de Loreto y Madre de Dios se convirtieron en una ruta hacia Brasil, sobre todo las ciudades de Brasiléia (Brasil) e Iñapari (Perú), no solo de peruanos o sudamericanos, también sirvió como medio para el ingreso de inmigrantes haitianos desde territorio peruano hacia Brasil con el fin de buscar trabajo. En 2010, Perú detectó el ingreso de haitianos de manera irregular desde Ecuador a través de «coyotes» ecuatorianos y peruanos, quienes los llevaron hasta las regiones de Madre de Dios y Loreto para luego cruzar a Brasil. Esta cifra de haitianos en suelo peruano se incrementó para 2011 (Tamagno, 2015).

En el mismo ańo, Brasil opta por suspender la concesión de refugio a inmigrantes haitianos, no obstante, la frontera peruana continuó siendo un camino de ingreso ${ }^{10}$. Ya para enero de 2012, Perú decidió brindar una visa temporal en calidad migratoria de turista a los haitianos lo que propició la disminución de los ingresos regulares de inmigrantes haitianos a 908, sin embargo, se calculó un aproximado de 200 entradas y salidas irregulares (Tamagno, 2015).

Actualmente, por la pandemia, en el mes de febrero inmigrantes — en su mayoría haitianos, senegaleses, indios, pakistaníes, entre otros - provenientes de la región Sur y Sudeste de Brasil pretendían entrar a Perú por Ińapari (Perú) con el objetivo de llegar a Estados Unidos, Guatemala o Haití. Por eso, el municipio de Assis (Brasil) pidió ayuda al gobierno estadual y federal para ayudar con abrigo y alimentación a los inmigrantes haitianos que quieren cruzar la frontera hacia Perú ${ }^{11}$.

El Ministerio de Relaciones Exteriores de Perú entró en contacto con sus pares en Brasil y Ecuador para buscar una solución debido a que la situación podría aumentar las mafias o los llamados coyotes ${ }^{12}$ así como afectar el paso de productos en la zona. La reunión bilateral entre la Autoridades de Madre de Dios (Perú) y Acre (Brasil), la Defensoría del Pueblo de Perú, Ministerio Público, Ejército Peruano, Policía Nacional del Perú, Migraciones, Dirección Regional de Salud, así como el Ministerio de la Mujer, Familia y Derechos Humanos y de la Policía Federal de Brasil ${ }^{13}$, coadyuvaron para la ayuda humanitaria, asistencia médica y la posibilidad de trasladar a los inmigrantes hasta Ecuador previa coordinación.

\footnotetext{
${ }^{10}$ Más información en https://www1.folha.uol.com.br/fsp/mundo/ft1502201115.htm

11 https://www1.folha.uol.com.br/mundo/2021/02/haitianos-retidos-na-fronteira-do-acre-rompem-barreira-eentram-no-peru.shtml

12 https://brasil.elpais.com/brasil/2021-02-20/fugindo-da-pandemia-no-brasil-haitianos-sao-reprimidos-na-fronteira-com-o-peru.html

${ }^{13}$ https://andina.pe/agencia/noticia-autoridades-peru-y-brasil-buscan-solucion-para-migrantes-haitianos-la-frontera-834529.aspx
} 


\section{Espacios de cooperación e integración}

Las relaciones bilaterales son multidimensionales porque permiten intereses políticos, económicos y sociales, los cuales son estratégicos. Durante las décadas de 1980 y 1990, las relaciones brasileñas se enfocaban en los ejes estratégicos argentino y venezolano, con el paso del tiempo fueron cambiando, mirándose hacia una estrategia que contemplara el Perú (Natalino et al., 2009).

Considerando los principios de neutralidad, no agresión, no interferencia, cordialidad y no indiferencia, el espacio regional comienza a tener un peso mayor en la consolidación de las relaciones internacionales brasileñas en Sudamérica (Pecequilo y Alves Do Carmo, 2015), por ejemplo, la mediación de Brasil ante el conflicto entre Perú y Ecuador a través del Acta de Brasilia en 1998. También, a partir de 2000, ante la necesidad de tener mayor presencia regional, se tomó en cuenta el eje peruano como una manera de complementar los ejes estratégicos argentino y venezolano (Natalino et al., 2009).

Producto de las estrategias de política externa brasileña, las relaciones diplomáticas se fortalecieron con el Perú, principalmente, durante el periodo de 2000 a 2015. Así, durante el gobierno del presidente peruano Alejandro Toledo (2001-2006), en 2002, se firmó la Declaración Conjunta creándose el mecanismo de consulta y coordinación política, también, el Acuerdo de cooperación técnica para el turismo, así como la Declaración de complementación económica que promovía la reciprocidad comercial y económica entre los países (Novak y Namihas, 2012).

Los vínculos diplomáticos entre el entonces presidente brasileño Luíz Inácio Lula da Silva y Alejandro Toledo sirvieron para acordar la construcción del puente internacional cerca a las ciudades de Ińapari (Péru) y Assis (Brasil), así como impulsar lo que sería la Iniciativa de Integración de la Infraestructura de la Región Suramericana (IIRSA), el acuerdo de cooperación para la conservación de flora y fauna silvestre en zonas amazónicas, el acuerdo de cooperación sobre vigilancia y protección de la Amazonía, entre otras (Novak y Namihas, 2012).

Las relaciones bilaterales tuvieron un entendimiento durante los gobiernos de Alan García y Luíz Inácio Lula da Silva lográndose dos declaraciones ministeriales ${ }^{14}$ y once tratados bilaterales ${ }^{15}$. En 2003, promovió la ruta interoceánica como un proyecto para la circulación de mercadería y personas en la Amazonía. En 2007, se iniciaron

\footnotetext{
${ }^{14}$ Declaración sobre la creación del mecanismo de consulta y cooperación entre los ministerios de Relaciones Exteriores y de Defensa del Perú y Brasil, y Declaración de los ministros de Defensa del Perú y el Brasil sobre vigilancia en la Amazonía (Novak y Namihas, 2012).

${ }^{15}$ Entre los que se encuentra, Memorándum de entendimiento sobre la lucha contra la pobreza y el hambre, Acuerdo complementario al Acuerdo básico de cooperación científica y técnica para la implementación del proyecto «Gestión
} 
obras para el sistema de carreteras multinacional con el fin de que ambos países tengan acceso a los océanos Pacífico y Atlántico, articular la Amazonía, mejorar el comercio internacional y el desarrollo regional (Natalino et al., 2009). Asimismo, se firmaron programas para apoyar a la población pobre y sobre gestión descentralizada de programas sociales.

En 2008, se priorizó los temas de cooperación y desarrollo fronterizos y de cooperación energética, por ejemplo, el proyecto de la central hidroeléctrica de Inambari la cual fue suspendida debido a las protestas sociales. En 2009, las relaciones se enfocaron en la mejora de las condiciones de vida de la población fronteriza y vinculación económica bilateral ${ }^{16}$ (Novak y Namihas, 2012). Ese año, se establecieron acuerdos de inversiones tanto privadas y públicas brasileñas en Perú con base en la cooperación e integración fronteriza, promoción del comercio y economía, políticas sociales, cooperación de fuerzas armadas, entre otras (Natalino et al., 2009).

Durante 2011 y 2012, hubo entrevistas entre los mandatarios, Ollanta Humala y Dilma Roussef. Las relaciones bilaterales tuvieron entre los principales temas las políticas sociales, comercio, inversiones, lucha contra el narcotráfico, vigilancia fronteriza y mejora de capacidad operativa de fuerzas armadas peruanas (Novak y Namihas, 2012).

\subsection{Integración Brasil y Perú, salida al Pacífico y al Atlántico}

Existe la idea de la integración económica sudamericana a través de megaproyectos que unan el Pacífico con el Atlántico como la Iniciativa de Integración de la Infraestructura de la Región Suramericana (IIRSA). Esta surgió en la cumbre de presidentes de América del Sur en 2000. IIRSA se constituyó como una apuesta en la integración física, un programa de infraestructura de transportes, energía y comunicaciones, coordinado intergubernamentalmente con el propósito de impulsar el proceso de integración social, económico y político, así como incentivar inversiones privadas en la región.

Por el Perú pasarían cuatro ejes de integración de desarrollo (EID): del Amazonas, la Andina, Interoceánica y Perú-Brasil-Bolivia. Específicamente, el eje del Amazonas fue elaborado considerando el sistema de transportes de puertos como Esmeraldas

\footnotetext{
descentralizada de los programas sociales»; Memorándum de entendimiento sobre cooperación en biotecnología, entre otras (Novak y Namihas, 2012).

16 Reunión en Río Branco, Acre (Brasil) entre los presidentes de Brasil y Perú, así como gobernadores regionales de Madre de Dios, Cusco, Arequipa, Tacna, Moquegua y Puno. Asimismo, se realizó el foro empresarial entre empresarios del sur peruano y de los estados brasileńos de Acre, Amazonas, Rondônia y Mato Grosso (Novak y Namihas, 2012).
} 
(Ecuador), Paita (Perú), Buenaventura (Colombia) y los puertos brasileños de Manaos, Belén y Macapá, este eje alcanzaría una superficie de 5657679 km², beneficiando una población aproximada de 61506049 habitantes. Por otra parte, el eje Interoceánica favorecería a Perú, Brasil, Bolivia ${ }^{17}$ y Chile $^{18}$, específicamente en Perú serían las regiones de Arequipa, Moquegua, Puno y Tacna y en Brasil los estados de Rio de Janeiro, São Paulo, Mato Grosso, Mato Grosso do Sul y Paraná.

El eje Perú-Brasil-Bolivia, alcanzaría una superficie de $3461461 \mathrm{~km}^{2}$, con aproximadamente 92594587 beneficiarios, tendría un área de influencia en los departamentos peruanos de Tacna, Moquegua, Arequipa, Apurímac, Cusco, Madre de Dios y Puno, asimismo, en los estados brasileños de Rondônia y Acre (Rhi-Sausi y Oddone, 2012). Actualmente cruzan por el Perú los ejes IIRSA Sur conocido como Interoceánica e IIRSA Norte que es el eje del Amazonas.

La concesionaria de IIRSA Norte conserva y opera la vía que junta el puerto marítimo de Paita con Yurimaguas, atravesando las regiones de Piura, Lambayeque, Cajamarca, Amazonas, San Martín y Loreto, siendo viable la interconexión del norte peruano con el Brasil. En el futuro, se planea el arribo de carga de importación para el sector Franca de Manaos (Brasil) a través del puerto de Paita (Perú), recorriendo IIRSA Norte hasta el Puerto COPAM (Yurimaguas) y descendiendo por la hidrovía del Amazonas hasta Manaos. Paralelamente, se pretende dejar el ingreso de la oferta exportable de la Macrozona Norte del Perú hacia el norte brasileño (Ministerio de Comercio Exterior y Turismo, 2018). Por otro lado, IIRSA Sur, se inició en 2006, y actualmente tiene construido los tramos 2 y 3 de la carretera Interoceánica Sur, uniendo las ciudades de Urcos (Cusco) hasta Ińapari (Madre de Dios) frontera con Brasil y Bolivia.

Tanto los ejes IIRSA Norte e IIRSA Sur son un medio para generar vínculos comerciales y económicos que beneficiaría a ambos países, considerando que los estados de la región norte de Brasil, como Acre, Rondônia y Amazonas, representan un mercado de 14,8 millones de habitantes, siendo una alternativa comercial, a lo que se suma el beneficio de cero por ciento de arancel a través del Acuerdo de Complementación Económica ACE 58. Además, Manaos y Belén cuentan con conexiones logísticas con el puerto de Callao en Perú (Ministerio de Comercio Exterior y Turismo, 2018).

En su momento, IIRSA se convirtió en una estrategia de inserción sudamericana, enfocada en el desarrollo de infraestructura (Fuccille, 2014) la cual podía pavimentar y vincular esa estrategia regional que tanto se anhelaba (Couto, 2013). El proyecto

\footnotetext{
${ }^{17}$ Se beneficiarían los departamentos de Beni, La Paz, Oruro, Potosí, Tarija, Cochabamba, Chuquisaca y Santa Cruz.

${ }^{18}$ Se beneficiarían las regiones de Arica, Parinacota y Tarapacá.
} 
fue útil para consolidar la integración y los intereses estratégicos regionales, no obstante, los cambios políticos y los hechos de corrupción que involucraron al sector gubernamental y empresarial afectaron el progreso del proyecto en la región, asimismo, existió una mercantilización de la función y el poder burócrata, ampliándose al ámbito de las relaciones bilaterales, debido a que se convirtió en un vehículo de control y de dominio.

Cabe subrayar que algunos autores como Zárate (2017) consideran que este tipo de proyectos están enfocados bajo un carácter más extractivista que integracionista de los pueblos ubicados en las fronteras, lo que menoscaba el desarrollo económico, propiciando la continuidad de las dinámicas de extracción y exportación de materia prima lo que es opuesto a una idea de colaboración estratégica regional, cooperación y desarrollo mutuo.

\subsection{Relaciones económicas y comerciales entre Brasil y Perú}

Las fronteras de Brasil y Perú se encuentran entre las once mayores fronteras del mundo, y las relaciones actuales y futuras de índole económica y comercial cobran más relevancias, tomando en cuenta que Brasil es la octava economía del mundo, su tasa de crecimiento del PIB real fue de 1,62\% en 2017, de 1,2 \% en 2018 y de 1,13\% en 2019. Asimismo, la composición del PIB en 2017 (por sector de origen) fue: en agricultura 6,6\%, en industria 20,7\% y 72,7\% en servicios. Además, en 2020, Brasil tiene una puntuación de 59,1 en el índice de facilidad para hacer negocios. Los principales productos agrícolas brasileños son la soya, caña de azúcar, mandioca, leche, arroz, naranja y aves (CIA, 2021).

De manera general, las exportaciones brasileñas hacia Perú entre 2010 y 2018 tuvo una variación del 10,63\%, mientras que las exportaciones peruanas hacia Brasil fueron de 81,03\%, asimismo, el intercambio comercial en ambos países es de 31,98\%. Específicamente, entre 2017 y 2018, la variación de las exportaciones de Brasil para Perú fue de $-1,55 \%$, las de Perú de $8,80 \%$, siendo el intercambio comercial de 2,51\%. Si bien Brasil no exportó mucho en comparación al Perú entre 2017 y 2018, las exportaciones brasileñas fueron mayores — Brasil tuvo 4867,65 y Perú 3300,10 millones de dólares en valor $\mathrm{FOB}^{19}$ —, debido a que exportan bienes de capital como automóviles, vehículos de carga, tractores y máquinas de construcción

\footnotetext{
${ }^{19}$ El FOB, free on board siglas en inglés, son las transacciones trasladas por mar o fluvial. El exportador es responsable por los costos de transporte y seguro de carga hasta que sea embarcada, el importador es responsable por el pago de transporte y de seguro a partir de ahí.
} 
que tienen valor agregado, en comparación con Perú que exporta productos tradicionales y no tradicionales ${ }^{20}$ (Ministerio de Comercio Exterior y Turismo, 2018).

Hay una necesidad de diversificar y exportar productos con valor agregado peruanos hacia Brasil porque es una manera de mejorar la balanza comercial peruana, así como impulsar conexiones entre los gobiernos subnacionales, el gobierno central y las empresas a través de oportunidades de negocios o comercio para promover la integración fronteriza (Novak y Namihas, 2012).

Las exportaciones e importaciones en frontera están a cargo de las intendencias de aduanas encargadas de la implementación, inspección y control aduanero en el territorio y el tránsito internacional de mercancías personas y medios de transporte, velar por el cumplimiento de la legislación aduanera, y de los convenios y tratados. Las principales intendencias aduaneras peruanas en las fronteras con Brasil son la Intendencia de Iquitos (Loreto), de Pucallpa (Ucayali) y de Puerto Maldonado (Madre de Dios), en el lado brasileño, se encuentran los puntos de frontera de la Receita Federal en Tabatinga (Amazonas) y las intendencias de Assis, Brasiléia y Rio Branco (Acre).

Tanto Brasil como Perú se ven fortalecidos por medio de acuerdos aduaneros como el Acuerdo de Complementación Económica $\mathrm{N}^{\circ} 58$ (comercio de bienes) el que establece disposiciones sobre reglas de origen, eliminación de las restricciones arancelarias y no arancelarias, medidas sanitarias y fitosanitarias, salvaguardias, entre otras. También está el acuerdo para el fortalecimiento de electricidad para exportación de los excedentes de Perú para Brasil (Ministerio de Comercio Exterior y Turismo, 2018). En 2020, la Superintendencia Nacional de Aduanas y de Administración Tributaria (SUNAT) junto con la Receita Federal de Brasil firmaron el Acuerdo de Reconocimiento Mutuo (ARM) de los programas Operador Económicos Autorizado (OEA), este acuerdo permitirá agilizar y facilitar las operaciones de comercio exterior con el fin de reducir costos y tiempo en actividades (Aduanas News, 2020).

Las rutas de IIRSA cobran relevancia por ser un medio para el comercio interno y nacional en ambos países, y coadyuva a la integración y cooperación transfronteriza, no obstante, no está siendo debidamente aprovechada en aspectos comerciales. A través de IIRSA Sur, entre 2012 y 2014, las exportaciones de Perú hacia Brasil aumentaron de 1928 775,00 (2012), 6471 286,00 (2013) y 8990 791,00 (2014), disminuyendo a 1740 696,00 (2015) y 4.082 245,00 (2016) millones de USD. En comparación con IIRSA Sur, la ruta de IIRSA Norte tiene 3161 018,00 (2012) y cae hasta 184 603,00 (2016) millones de USD.

\footnotetext{
${ }^{20}$ Las exportaciones peruanas no tradicionales al Brasil son la lechuga, calabacín, coliflor, sandía, melón, tomate, palta, ajo, espárragos, papa, betarraga, cebolla, zanahoria, frijol, manzana, pera, repollo, mandarina, tangelo, uva, arándano, granadilla, café, chía, quinua, ajonjolí, tabaco, hojas, orégano y hongos comestibles. Y cuatro del sector pesca, como la pota, caballa congelada, cazones, merluza congelada, conserva de pescado, langostinos
} 
Gráfico 1. Intendencias aduaneras peruanas y brasileñas en frontera

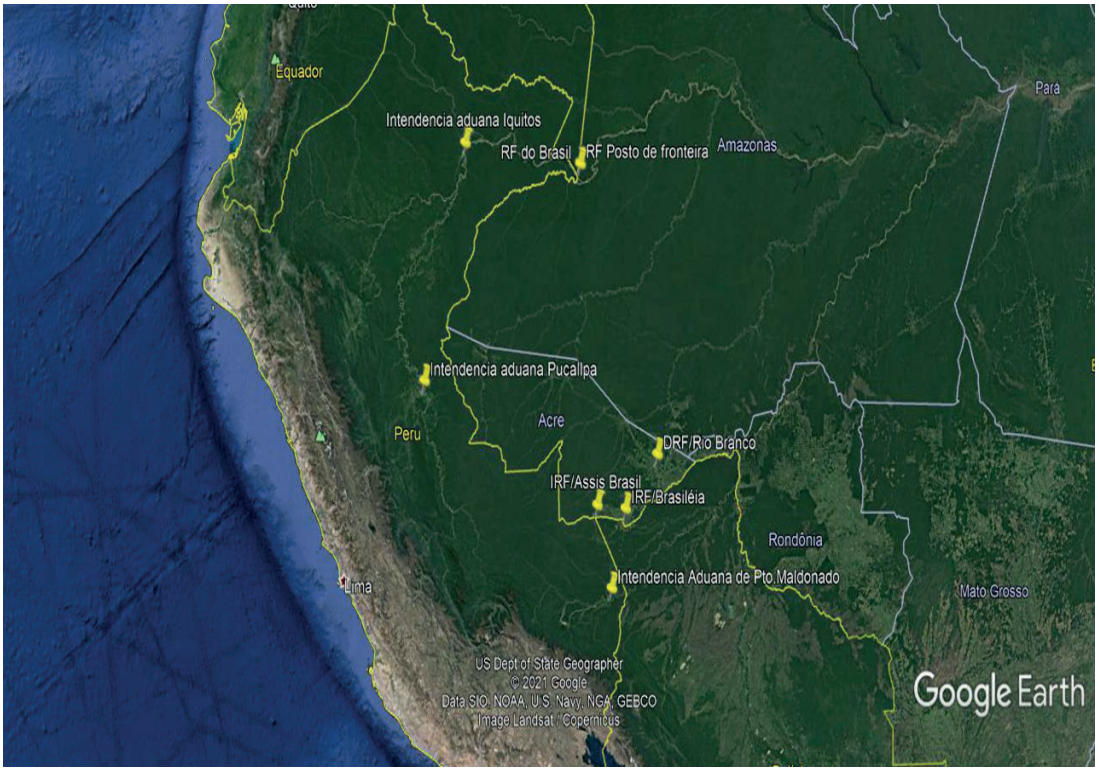

Fuente: Receita Federal, s.f.; SUNAT, s.f.

Gráfico 2. Evolución de las exportaciones de Perú hacia Brasil por IIRSA Sur e IIRSA Norte, periodo 2012-2016 (valor FOB en millones de USD)

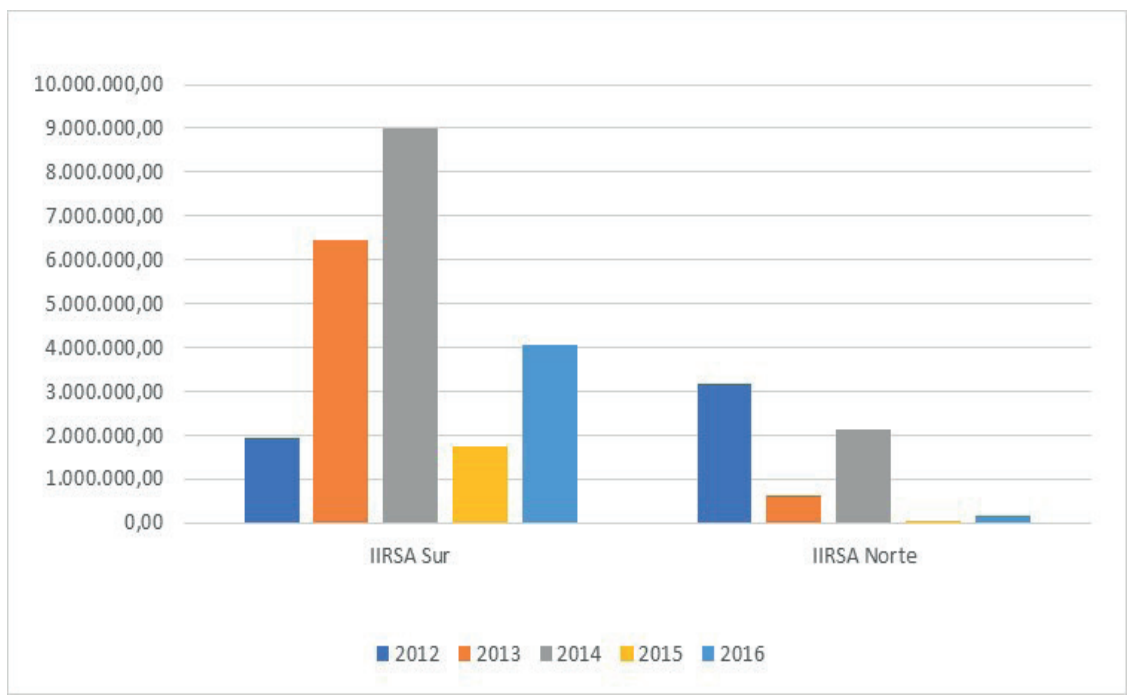

Fuente: Ministerio de Comercio Exterior y Turismo, 2017. Elaboración propia. 
En 2015, los principales productos peruanos exportados hacia los estados de Acre y Rondônia eran aceitunas en conserva, uvas, cebolla fresca y refrigerada, quinua, cementos Portland y tejidos de algodón. Obteniendo mayores ganancias en la exportación de cementos Portland y aceitunas en conserva.

Tabla 5. Principales productos exportados a los estados de Acre y Rondônia vía Interoceánica 2015

\begin{tabular}{lrr}
\hline Productos & Cantidades (kg) & Valor (USD) \\
\hline Aceitunas en conserva & 706627,00 & 804786,00 \\
Uvas frescas & 165707,00 & $328.553,00$ \\
Cebollas frescas o refrigeradas & 578700 & 243963,00 \\
Quinua & 32000 & 83912,00 \\
Demás granos y cereales, aplastados en copos & 40,98 & 110664,00 \\
Cementos Portland & 3539275,00 & 432914,00 \\
Tejidos de algodón & 9329,00 & 82763,00 \\
\hline
\end{tabular}

Fuente: Ministerio de Comercio Exterior y Turismo, 2015. Elaboración propia.

Con respecto a Brasil, en el periodo 2010-abril 2021, las exportaciones del estado fronterizo de Amazonas hacia Perú paulatinamente disminuyó, específicamente, en 2010, Amazonas tuvo 53450 933,00 USD en valor FOB, sufriendo una caída progresiva hasta llegar a 8296361,00 USD en 2015, a partir de esa fecha las exportaciones se redujeron más.

Para el caso del estado de Acre, en 2010 era de 1134709 USD en valor FOB, aumentando en 2015 a 7542 289,00 USD, en 2018 alcanzó los 9478 148,00 USD.

Los datos de las tablas anteriores nos muestran que las exportaciones de los estados brasileños de Amazonas y Acre, así como las exportaciones de Perú por las rutas de IIRSA Norte y Sur eran mayores hasta 2014, a partir de 2015 las exportaciones han ido disminuyendo progresivamente 
Gráfico 3. Exportaciones del estado de Amazonas y Acre hacia Perú, en valor FOB (USD)

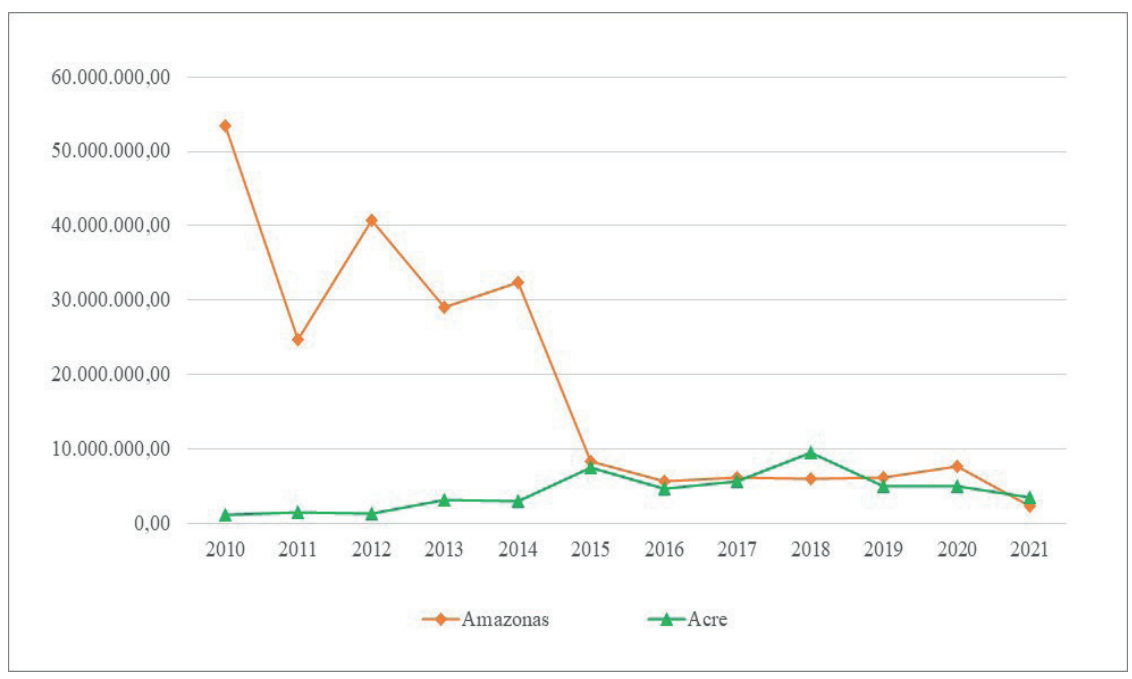

Fuente: Comex Stat. Ministério da Industria, Comércio Exterior e Serviços. Elaboración propia.

\section{Consideraciones finales}

Las fronteras son instrumentos de socialización y desarrollo y convergen diferentes actores sociales, económicos e institucionales. Las fronteras compartidas entre Perú y Brasil son de interés estratégico por su biodiversidad, ríos y lagunas, variedad cultural, su ubicación que permiten el acceso tanto al océano Pacífico como el Atlántico. También, por ser una zona selvática, las fronteras están expuestas a actividades ilícitas o inmigración irregular, por eso la relevancia de crear y fortalecer mecanismos de integración y cooperación tanto a nivel nacional como subnacional. El papel de los gobiernos regionales y locales deben ser considerados estratégicos, ya que coadyuvan a la participación multinivel, la protección de bienes históricos y culturales, la elaboración de políticas públicas de abajo hacia arriba, el desarrollo local en salud y educación y la protección de infraestructura crítica.

En relación con la variación de la población urbano y rural en las regiones de frontera, para el caso de Perú, la variación de población rural disminuyó en -18\% (85 953 habitantes), mientras que la urbano aumentó en 18\% (173 546); en Brasil, la población rural aumentó en 4\% (333 722 habitantes) y urbana en 33\% (813 461), con una variación de $25 \%$. Asimismo, el crecimiento poblacional en las regiones fronterizas peruanas aumentó $6 \%$ en diez ańos, en cambio en los estados fronte- 
rizos brasileños aumentó en un $25 \%$ en diez años. El estado de Amazonas es el que posee mayor población seguido de Loreto y Acre, no obstante, la mayor densidad poblacional se encuentra en la región de Ucayali. Además, ambos países tienen una población joven en frontera que oscila entre los 0 a los 19 años.

Considerando el Índice de Desarrollo Humano los niveles más altos son de los estados de Amazonas $(0,674)$ y Acre $(0,663)$. Con relación a la inversión pública, el presupuesto público per cápita mensual más alto está en la región de Acre con 1458 USD. Una manera de medir la economía formal en la zona es a través de la bancarización, los datos muestran que existe una mayor inserción de bancarización en el estado de Amazonas con 207 agencias, muy por encima de las demás regiones. La mayor tasa de desempleo en frontera se encuentra en los estados brasileños, en cambio las regiones peruanas fronterizas tienen un mayor ingreso promedio en dólares. Sin embargo, en Índice de Desarrollo Humano, inversión pública, presupuesto público per cápita mensual, y la inserción de bancarización son mejores en los estados brasileños que en las regiones peruanas.

Las características singulares de los espacios fronterizos repercuten en la organización y dinámica social, desde las características demográficas, sociales, económicas hasta las dinámicas de movilidad en fronteras, ello permite reflexionar sobre el funcionamiento e identificación en las mismas. Perú tiene un desplazamiento más de turistas locales en comparación con Brasil. Además, el punto de control fronterizo más importante es Ińapari ubicado en Madre de Dios. Por el lado de Brasil, el estado de Acre tiene mayores desplazamientos de personas, de los cuales, la mitad son peruanos que transitan hacia Brasil.

En relación con las actividades ilícitas, Perú es el segundo productor de hoja de coca después de Colombia. Las fronteras entre Perú y Brasil son una ruta para traspasar cocaína hacia Europa y África, especialmente, en la frontera tripartita con Colombia. Por eso, tanto Brasil como Perú tienen acuerdos para controlar y vigilar los espacios aéreos en la frontera lo que permitió operaciones conjuntas. No obstante, la presencia de pobreza, narcotráfico, actividades conexas y políticas de centro-periferia en estas fronteras disminuyen la presencia de integración y cooperación transfronteriza, la paradiplomacia y políticas públicas bottom-up.

Perú y Brasil tienen acuerdos comunitarios como Mercosur o el convenio bilateral firmado en 2004, que permite a los inmigrantes facilidades para sus ciudadanos en ambos países. Sin embargo, las ciudades cerca de la frontera como Brasiléia e Ińapari son usadas como ruta de ingreso de inmigrantes en condición irregular, sobre todo de haitianos que van de Perú hacia Brasil para conseguir trabajo. Estos hechos se iniciaron en 2010 hasta la actualidad, tanto Brasil como Perú han realizado políticas 
migratorias para disminuir el pase irregular. A razón de la pandemia las ciudades fronterizas se vieron afectadas por el cierre de fronteras porque inmigrantes de diferentes nacionalidades intentan pasar de Brasil hacia Perú con el fin de regresar a sus países. Los ministerios, policía, instituciones y gobiernos subnacionales de frontera cooperaron de manera conjunta para resolver este impase.

Es pertinente mejorar las vías de comunicación y distribución de los productos a través de las fronteras y reforzar o encontrar propuestas similares a la Iniciativa de Integración de la Infraestructura de la Región Suramericana (IIRSA). Tanto los ejes IIRSA Norte e IIRSA Sur son un medio para generar vínculos comerciales y económicos que beneficiaría a ambos países. Las relaciones bilaterales y fronterizas pueden coadyuvar a mejorar el mercado de productos brasileños, reforzar la institucionalidad nacional y subnacional, impulsando políticas públicas bottom-up y de carácter integracionista en las fronteras y ser una oportunidad para afianzar la integración, cooperación y paradiplomacia.

Brasil y Perú tienen acuerdos aduaneros, siendo las intendencias aduaneras en frontera responsables de velar el cumplimiento de estos, así como de implementar, inspeccionar y controlar la mercancía aduanera en territorio y tránsito internacional. Las rutas de IIRSA Norte y Sur, cobran relevancia por ser medios para el comercio interno y nacional en ambos países, y coadyuvan a la integración y cooperación transfronteriza, no obstante, no está siendo debidamente aprovechada en aspectos comerciales. El aún reducido comercio entre las regiones fronterizas influye en la integración y en las relaciones bilaterales, las eliminaciones recientes sobre las restricciones arancelarias y no arancelarias, medidas sanitarias y fitosanitarias, y salvaguardias pueden contribuir a mejorar el comercio entre los mismos.

Tomándose las tres características sobre cooperación transfronteriza se puede decir que hay un camino inicial hacia la cooperación, sin embargo, debe considerarse proyectos de cobertura transnacional y aún deben verse fortalecidas estas condiciones, sobre todo, en lo relacionado con cooperación de los municipios como articuladores que trabajen en forma de red en el área internacional para coadyuvar en proyectos de cooperación, ya que la integración regional es un instrumento para el desarrollo económico y social, la gobernabilidad y la inserción económica internacional. 


\section{Referencias bibliográficas}

Aduanas News. (2020). Perú y Brasil firman Acuerdo de Reconocimiento Mutuo de sus Programas OEA. Aduanas news. https://aduananews.com/ peru-y-brasil-firman-acuerdo-de-reconocimiento-mutuo-de-sus-programas-oea/

Aristimunho Vargas, F. (2017). Formação das fronteiras latino-americanas. Fundação Alexandre de Gusmáo.

Banco Central de Reserva del Perú [BCRP]. (s.f.). Estadisticas. https://www.bcrp.gob.pe/estadisticas.html

Central Intelligence Agency [CIA]. (2021). The World Factbook. https://www.cia.gov/ the-world-factbook/countries/brazil/\#economy

Chiarello, L. M. (2011). Las politicas públicas sobre migraciones y la sociedad civil en América Latina. Los casos de Argentina, Brasil, Colombia y México. Scalabrini International Migration Network.

Comisión de Promoción del Perú para la Exportación y el Turismo. (2018a). Perfil del turista interno que visita Loreto.

Comisión de Promoción del Perú para la Exportación y el Turismo. (2018b). Perfil del turista interno que visita Madre de Dios.

Comisión de Promoción del Perú para la Exportación y el Turismo. (2018c). Perfil del turista interno que visita Ucayali.

Comisión Económica para América Latina y el Caribe. [CEPAL]. (s/f.a). CEPALSTAT | Bases de Datos y Publicaciones Estadisticas. https:/estadisticas.cepal.org/cepalstat/ Perfil_Nacional_Social.html?pais=PER\&idioma=spanish.

Comisión Económica para América Latina y el Caribe. [CEPAL]. (s./f.b) Indicadores demográficos interactivos. Cepal. https://www.cepal.org/es/ indicadores-demograficos-datos-interactivos

Comisión Económica para América Latina y el Caribe. [CEPAL]. (2012). IMILA: Investigación de la Migración Internacional en Latinoamérica. Banco de datos CELADE. https://celade.cepal.org/bdcelade/imila/

Constituição da República Federativa do Brasil. (1988).

Constitución Política del Perú. (1993).

Couto, L. (2013). Relaçôes Brasil-América do Sul: a construção inacabada de parceria com o entorno estratégico. Parcerias estratégicas do Brasil (pp. 195-217). Fino Traço

De Souza, E. (2013). Por uma Cooperação Transfronteiriça: Algumas Contribuiçóes para as Dinâmicas Territoriais da Fronteira Brasil-Paraguai. Revista GeoPantanal, 63-78.

Departamento de Estudios Económicos. (2018a). Loreto: Sintesis de Actividad Económica. Banco Central de Reserva del Perú, Sucursal Iquitos

Departamento de Estudios Económicos. (2018b). Madre de Dios: Sintesis de Actividad Económica. Banco Central de Reserva del Perú, Sucursal Cusco.

Dias, M.G. (2015). Cooperaçôes Bilaterais do Brasil com Bolívia, Colômbia e Peru no Combate ao Tráfico de Drogas Ilícitas. I Seminário Internacional de Ciência Política (SICP). Universidade Federal do Rio Grande do Sul. 
Fuccille, A. (2014). O brasil e a América do Sul: (re)pensando a segurança e a defesa na regiāo. Revista Brasileira de Estudos de Defesa 1(1). https://doi.org/10.26792/rbed. v1n1.2014.49245.

García Pinzón, V. (2018). Dimensiones locales de la seguridad y la cooperación transfronteriza en la frontera amazónica de Brasil, Colombia y Perú. OPERA, (23), 59-80. https://doi.org/10.18601/16578651.n23.05.

Haesbaert, R. (2004). O mito da desterritorialização: do "fim dos territórios á multiterritorialidade. Bertrand Brasil.

Instituto Brasileiro de Geografia e Estatística. (2010a). Sinopse do Censo Demográfico 2010. Acre. https://censo2010.ibge.gov.br/sinopse/index.php?dados=22\&uf=12.

Instituto Brasileiro de Geografia e Estatística. (2010b). Sinopse do Censo Demográfico 2010. Amazonas. https://censo2010.ibge.gov.br/sinopse/index.php?dados=0\&uf=13

Instituto Nacional de Estadística e Informática [INEI]. (2017a). Censos Nacionales 2017. Loreto.

Instituto Nacional de Estadística e Informática [INEI]. (2017b). Censos Nacionales 2017. Madre de Dios.

Instituto Nacional de Estadística e Informática [INEI]. (2017c). Censos Nacionales 2017. Ucayali.

Instituto Peruano de Economía [IPE]. (2020). Índice de competitividad regional. https:// incoreperu.pe/portal/index.php/databank.

Jorge, A. (1999). RIO BRANCO E AS FRONTEIRAS DO BRASIL. Uma introdução às Obras do Barão do Rio Branco. Senado Federal.

Landim, H. (2015). SISFRON: ferramenta de ampliação da Diplomacia Militar brasileira e fortalecimento do CDS. Revista Política Hoje, 24(1), 135-148.

Luján, P.M. (2017). Geopolítica, conflictos fronterizos en América Latina. Revista Geopolítica Transfronteiriça, 1(1), 1-14.

Ministério da Industria, Comércio Exterior e Serviços do Brasil. (s./f.). Comex Stat. http:// comexstat.mdic.gov.br/pt/home

Ministerio de Comercio Exterior y Turismo del Perú. (2017). Aprovechamiento de los corredores interoceánicos en el comercio bilateral con Brasil y con el exterior.

Ministerio de Comercio Exterior y Turismo del Perú. (2018). Oportunidades para el desarrollo de la macro región norte con Brasil.

Ministerio de Trabajo y Promoción del Empleo del Perú. (2019a). Región Loreto: Panorama laboral.

Ministerio de Trabajo y Promoción del Empleo del Perú. (2019b). Región Madre de Dios: Panorama Laboral.

Ministerio de Trabajo y Promoción del Empleo del Perú. (2019c). Región Ucayali: Panorama laboral.

Ministério de Turismo do Brasil. (2012). Caracterização e dimensionamento do turismo doméstico no Brasil - 2010/2011. Relatório Executivo. Produto 6. Fundação Instituto de Pesquisas Econômicas. 
Ministério de Turismo do Brasil. (2018). Anuário Estatístico de Turismo - 2018.

Natalino, E. C., Alves do Carmo, C. Pacheco Paes Barreto, I. y Fundação Alexandre de Gusmão. (2009). Peru: evolução recente e futura. FUNAG.

Neto, W. A. D. y Penha, B. (2016). As regióes de fronteira como laboratório da integraçáo regional no Mercosul. http://repositorio.ipea.gov.br/bitstream/11058/8742/1/As\%20 Regi\%C3\%B5es\%20de\%20fronteira.pdf

Novak, F. y Namihas, S. (2012). Las relaciones entre el Perú y Brasil (1826-2012). Instituto de Estudios Internacionales/Pontificia Universidad Católica del Perú.

Oddone, N. (2014). Cooperación Transfronteriza en América Latina: Una aproximación teórica al escenario centroamericano desde la experiencia del Proyecto Fronteras Abiertas. Revista Oikos, 13(2), 129-144.

Pecequilo, C. S. y Alves do Carmo, C. (2015). A política externa e a América do Sul. En $O$ Brasil e a América do Sul. Relaçôes regionais e globais. Alta Books.

Porras Barrenechea, R. (1926). Historia de los limites del Perú. Casa Editorial E. Rosay.

Presidencia del Consejo de Ministros del Perú. (2007). Define y establece las Politicas Nacionales de obligatorio cumplimiento para las entidades del Gobierno Nacional.

Receita Federal. (s./f.) Pontos de Fronteiras. https://receita.economia.gov.br/ orientacao/aduaneira/importacao-e-exportacao/recinto-alfandegados/ pontos-de-fronteiras-alfandegados-1

Rhi-Sausi, J. L. y Oddone, N. (2012). Cooperação transfronteiriça e integração: oportunidades para o desenvolvimento do Peru. http://repositorio.ipea.gov.br/bitstream/11058/6224/1/RTM_v4_n1_Coopera\%C3\%A7\%C3\%A3o.pdf

Salisbury, D. S. y Fagan, C. (2013). Coca and Conservation: Cultivation, Eradication, and Trafficking in the Amazon Borderlands. GeoJournal 78(1), 41-60. https://doi. org/10.1007/s10708-011-9430-x.

Superintendencia Nacional de Aduanas y de Administración Tributaria [SUNAT]. (s/f.). Dependencias y oficinas a nivel nacional. SUNAT. https://www.sunat.gob.pel institucional/quienessomos/dependenciasoficinas_ad.html

Tamagno, C. (2015). Situación de los migrantes extranjeros en el Perú y su acceso a servicios sociales, servicios de saludy educación. Documento de trabajo. Organización Internacional para las Migraciones.

Vargas, F.A. (2017). Formação das fronteiras latino-americanas. Fundação Alexandre de Gusmão.

Zárate Botía, C. G. (2017). Estado, conflictos ambientales y violencia en la frontera amazónica de Brasil, Colombia y Perú. Revista de Paz y Conflictos, 113-136.

Fecha de recepción: 18 de abril de 2021 Fecha de aprobación: 30 de julio de 2021 